\title{
The UNCTAD III Resolution on the Transfer of Technology
}

\section{by Anthony Connors}

It is natural enough that UNCTAD should be concerned about the international transfer of technology, for the problems that are discussed under this heading are typically about the relations between large firms possessing technological 'quasi-monopolies' (as well as other kinds of monopolistic advantage) and under-developed countries. There is a contradiction between the needs for new production technologies in under-developed countries (though the precise nature of these 'needs' could do with closer examination) and the terms and conditions on which technology is supplied. The technologies might be needed for 'development' in some general sense, but it often turns out that they can only be got on terms which themselves create obstacles to development. This type of problem in international economic relations is precisely what UNCTAD is about.

UNCTAD's involvement is understandable from another point of view. Much of the recent concern about 'transfer of technology' has been part of a wider concern about the limitations of the kind of import-substituting industrialisation which UNCTAD itself supported some years ago. This does not mean that the problems associated with technological monopolies are only found in import-substituting economies. It is simply that one's attention is naturally drawn to technology transfer problems as soon as one poses the question: "What are the developmental implications of import-substitution policies when the import-substituting is done by foreign firms, or on the basis of foreign technologies?". These are questions that were not asked in the Prebisch era, although with the advantages of hindsight it is easy to see that they are significant questions to ask about Prebisch-type policies. And it is highly appropriate for this reason too, that they should be raised in UNCTAD.

UNCTAD III passed a resolution on the transfer of technology [Resolution 39 (III)], which is the nearest [NCTAD has got to an international agreement on the importance and relevance of the

*Anthony Connors is a student of Development. 
subject. The resolution has a rather special place in the annals of Santiago, because it passed the plenary discussion without objection (though we think there were some stated reservations). It has been widely interpreted as the success of UNCTAD III - one of the few things on which there was agreement.

On the face of it, there is something of a puzzle here: How is it that the conference could agree on this question - which is at least as controversial and fundamental as many of the things on which agreement was impossible? Is it simply that the resolution contains nothing of significance, or is there a real agreement on real issues?

One cannot answer these questions without knowing a little of the prior history of transfer of technology in UNCTAD. In all probability, it started quite a long while back - possibly in internal discussions in the Secretariat, or between the Secretariat and the UNCTAD delegations. There must have been a period of labyrinthine inter-agency debate. But we can take as given the flow of memoranda and the artful manoeuvre that inevitably precedes any 'initiative' in the UN system. The first public sign that something was happening was a decision by the Trade \& Development Board of UNCTAD - suitably buttressed by references to a small mountain of inter-agency communications, memoranda and the like - that there should be something called an Intergovernmental Group on Transfer of Technology. This group (on which 45 governments are represented) is to prepare a programme of work for UNCTAD; it has to identify obstacles and problems in the transfer of technology and consider possibilities for the development of international and national action. An UNCTAD Intergovernmental Group (I.G.G.) is not a permanent committee; it has a specified life, after which it might be turned into a committee or disbanded.

This particular I.G.G. is probably a compromise. The developing countries were insistent that they wanted something done about the transfer of technology and the issue could not be shelved. Group $B$ (the advanced market economies) were not particularly anxious to make much of the issues, and anyway, are generally very anxious to restrict the growth of the international secretariats. The I.G.G. is a half-way house between a permanent committee and doing nothing. Its very existence is subject to review - and it is not empowered to start international negotiation - only to propose areas where there might be some 'action'. At the same time, the Intergovernmental Group makes the working decisions on the orientation of effort within UNCTAD, and on the conclusions and proposals that come out of the secretariat programme. 
It was, however, something of an achievement to get the I.G.G. set up at all. Even though it is the product of a compromise, it has the power to discuss the 'transfer of technology' in a realistic way. Until it was set up, most of the work in the UN on technology transfer was about politically anodyne (though practically important) problems like finding more 'appropriate' technologies for the developing countries. And discussions of the problem between the governments of the advanced countries normally concluded that they could be solved if only the developing countries would give adequate incentives to foreign private direct investment, and to advanced country enterprises that have technology to licence. The I.G.G. is the first international forum which has the power to discuss the thorny political and economic issues that arise when one faces realities: e.g. that 'technology' is very often a form of industrial property, which confers monopolistic advantages on the firms which have it; and that the patent system is a support for the private 'ownership' of knowledge about production. Obviously the re is no consensus about the importance of these realities. Some advanced country governments argue that the whole question has been vastly exaggerated. But it is a considerable achievement to have generated an international debate on issues which until a short time ago were mainly discussed in the underground economic literature.

UNCTAD had equipped itself with the Intergovernmental Group before Santiago; there was already an agreed programme and some work on the problem within the Secretariat. Any assessment of the significance of the Conference Resolution on Technology must take account of this. The real question about the resolution is whether or not it is a real advance on what had anyway been achieved before the Conference started.

There is something to be said for the claim that there were some gains at Santiago. At least the Conference did not disband the I.G.G. and in fact confirmed its mandate. This however is not much of an achievement, since it would have been very difficult politically for any government to have voted against the existence of a committee which already had an approved programme.

But the Conference resolution has apparently made some net additions to UNCTAD's activities in this field. It explicitly encourages the developing countries to tackle questions like 'registration, review and approval of agreements involving transfer of technology', 'negotiation of contracts' and assisting domestic enterprises in finding alternative suppliers of technology. It recommends that developing countries should exchange information amongst themselves on their experiences. All these points are directly relevant to the 
bargaining position of developing countries vis-à-vis technology suppliers .

There is also a recommendation that advanced countries should 'facilitate an accelerated transfer of technology' in various ways, mainly by providing forms of technical assistance and information and by "endeavouring to provide possible incentives to their enterprises to facilitate an accelerated transfer of their patented and unpatented technologies... on fair and reasonable terms." These particular clauses about what developed countries should do are ambiguous. The main emphasis is on getting more transfers to take place, which is not necessarily desirable. It would be too easy for the advanced countries to claim that policies they may have already which create incentives for their companies to invest in developing countries met these recommendations - though it is most unlikely that this is what the developing countries have in mind, and it is certain that these policies beg all the important questions about technological monopoly ("fair and reasonable terms" notwithstanding). There is however one recommendation to the advanced countries which is much more to the point, namely, that they should "participate actively in the identification of restrictive business practices affecting the transfer of technology...". Of course, it is a long way from an UNCTAD recommendation to actual action and there is no guarantee here that advanced countries will co-operate actively with developing countries on restrictive practices - but it is something to have got the recommendation included.

The recommendations to the Secretariat go a little beyond the I.G.G. mandate in two further respects. First UNCTAD is now allowed to give technical assistance to developing countries on the transfer of technology (there will be U.N.D.P. funds for this) and to provide training for personnel from these countries. Second, there is a specific request that the international patent system should be reviewed. Both of these are distinct advances for the Secretariat programme not simply because they increase its size and area of responsibility (which is not necessarily a good thing), but because they bring the secretariat into much more immediate contact with the realities in the developing countries themselves.

Clearly there were some advances from the position that UNCTAD had reached when it set up the I.G.G. They were however small advances; there is still no real agreement between Croup $B$ and the ' 77 ' that this is an issue for negotiation. More precisely, it is in the interest of most Group $B$ countries to avoid international debate on these issues - and UNCTAD III failed to find the arguments to force them into negotiation. The recommendation on restrictive practices gets near the mark, but it is only a recommendation; the re is no 
commitment to do anything. Indeed, from some points of view the advance has been miniscule. Some advanced country representatives apparently brought out the old chestnut that technology transfer is done by private companies, and their governments do not interfere with free enterprise. This is now an ancient line of defence: there is no claim that the 'invisible hand' is working to the advantage of everyone - including the developing countries - only an assertion that nothing can be done about the matter (presumably even if it turns out to be harming the developing countries). It is a measure of the slowness with which the discussion is unfolding that people can make this kind of argument without being laughed out of the comittee room.

In some places, because of the influence of Group B countries, the resolution is quite strongly influenced by the platitude that the more foreign investment the developing countries can get, the better (for whom?). This, also, is a small step backward from the more realistic and intellectually tenable position that has grown up in the discussions of the I.G.G. As far as this part is concerned, the resolution is rescued from triviality (but only just), by the piece on restrictive practices

There was no advance on the question of the I.G.G.: Will it continue to have an existence after its first report to the Trade \& Development Board? Will 'transfer of technology' become a question of comparable importance to 'aid \& trade' in the UNCTAD system? Not only are these still unanswered questions, but there is still doubt about how the decisions on them will be taken. Will other agencies have a role in a review of the work of the I.G.G., or will it be done by UNCTAD alone? There is still a possibility that secretariat rivals in other agencies (and there are many), together with the 'opposition' delegates (mainly in Group B) could combine to quash the whole thing when the I.G.G. mandate expires. UNCTAD III did nothing to avert the danger.

But the Resolution is limited in a more important way. Whilst the future of the I.G.G. is an undecided matter, the fact remains that it is the effective arbiter of what goes into the secretariat programme of work and of the degree of priority that attaches to any particular part. It may be politically difficult for the I.G.G. to ignore a Conference recommendation; it is nevertheless possible to diminish the effect of any particular proposal by putting restrictions on the availability of resources to carry it out. One does not really know what significance to attach to the limited gains that were made at Santiago, until one has some idea of whether or not the Secretariat will get the money and the people it needs to make a proper job. And since the $U N$ as a whole is suffering from a severe shortage of funds, a delegation which wishes to restrict the activities of the secretariat in any particular field, can usually find 
strong budgetary arguments to support its case. It can often rely on support from within the UN system - because the various agencies in the 'UN family' bicker about resources at the best of times - and fight like hell at times when the budget is restricted.

The reasons why it was possible for UNCTAD III to agree to the resolution are not difficult to comprehend. Nearly all the proposals of substance which the Conference was asked to underwrite had been agreed before, at the time the I.G.G. was set up. And any delegation which might have reservations about such additions as were made to the mandate, knows that there is a 'fail-safe' device at hand. It can effectively re-open the whole question in the I.G.G., where its opposition can be conducted on the pragmatic grounds that there just isn't any money to do the job.

A number of other factors probably contributed to the relative ease in passing the resolution. For one thing UNCTAD delegations are not yet acclimatized to this type of discussion. This probably makes it easier to reach an agreed text without hours of Byzantine argument over commas and semi-colons. And those delegations which are fully aware of the possible implications of the debate are content to cross the bridges when they come to them. Many Group B countries probably hope there will be no debate at all. The developing countries, correctly, would like a better supply of facts and empirical analysis before they start in on it.

A second contributory factor was the relatively high degree of unity amongst the ' $77^{\prime}$. This is an issue on which unity might be relatively easy to achieve, and to what extent the discussion at Santiago might have some salutary side-effects for the ' $77^{\prime}$, if only as a reminder of times past.

Finally, the Secretariat appears to have played an important part. The UNCTAD secretariat dealing with these problems is enthusiastic and hard-working. It has the confidence of the vast majority of delegations on either 'side' of the debate - and there is every reason why it should. The secretariat was anxious to get a clear mandate from UNCTAD III and worked hard to get it.

Thus the resolution passed easily, not because it is without significance, but because most of what it contained had been discussed and agreed before. It was certainly worthwhile to have UNCTAD III confirm the mandate of the I.G.G., but hardly surprising that it could do little more. The programme of analysis which the I.G.G. started in $1970 / 71$ is still only a programme; there are few substantive proposals for action as yet. The real political debate cannot start until there are proposals. In the circumstances representatives 
of the developing countries at UNCTAD III were content to confirm the principle that UNCTAD should busy itself with the problems because there was really little else they could do. The advanced countries could not force a retreat from the Intergovernmental Group even if they had wanted to, so that they were content with a few tactical adjustments to the terms of the resolution. Anyway, the really important decisions will be made in the I.G.G. Meanwhile, the Secretariat is collecting empirical evidence, in preparation for a real debate. But even then, of course, there will be the long road from international argy-bargy to action. In the meantime the developing countries would be well advised to take action themselves, particularly by comparing notes on the experiences they have had in negotiating with foreign enterprise. OPEC has shown that collective action of this kind is an effective way to strengthen one's bargaining position - and that is what it is all about. 